ORIGINAL ARTICLE

\title{
Involved-field Radiation Therapy for Patients with Stage III Non-small-cell Lung Cancer: Early Results of Hypofractionated Involved-field Radiation Therapy
}

\author{
Katsumaro Kubo'; Hiroshi Kiriu ${ }^{1}$
}

\begin{abstract}
Objective. To evaluate the outcomes after treating patients with stage III non-small-cell lung cancer (NSCLC) using involved-field radiation therapy (IFRT) without elective nodal irradiation and to evaluate the effects of hypofractionated IFRT. Methods. From December 2004 to November 2015, 51 patients with advanced NSCLC underwent IFRT. Of these, 45 patients were enrolled and evaluated. The median age was 69 years (range, 50-89 years), and 42 patients were men and 3 women. Eleven patients (24.4\%) presented with adenocarcinoma, 30 (66.7\%) with squamous cell carcinoma, and 4 (8.9\%) with other types. Twenty-four (53.3\%) had stage IIIA and 21 (46.7\%) had stage IIIB. In patients treated by conventional IFRT, normal fractionation was used (2 $\mathrm{Gy} /$ fraction), and the total prescribed dose ranged from 60 to $66 \mathrm{~Gy}$. In patients treated by hypofractionated IFRT, $2.5 \mathrm{~Gy} /$ fraction was used, and the total prescribed
\end{abstract}

dose ranged from 65 to 70 Gy. Results. The 1- and 2-year overall survival rates were $78.4 \%$ and $53.7 \%$, respectively. The 1- and 2-year local control rates were $72.2 \%$ and $57.7 \%$, respectively. The patients in the conventional IFRT group had a 1-year local control rate of $61.2 \%$ and a 2 -year local control rate of $47.6 \%$, while the patients in the hypofractionated IFRT group achieved higher local control rates of $87.1 \%$ and $72.5 \%$, respectively $(\mathrm{P}=0.0465)$. Conclusions. IFRT for patients with stage III NSCLC is feasible, and the incidence of elective nodal failure was low. Hypofractionated IFRT may therefore contribute to improvements in local control and overall survival.

(JJLC. 2016;56:1003-1011)

KEY WORDS — Involved-field radiation therapy (IFRT), Non-small-cell lung cancer (NSCLC), Chemotherapy

\section{INTRODUCTION}

At present, the standard evidence-based treatment for advanced non-small-cell lung cancer (NSCLC) is concurrent chemoradiation. During standard radiotherapy for NSCLC, elective nodal irradiation (ENI) to the entire mediastinum, supraclavicular fossa, and ipsilateral hilum has been deemed necessary even without evidence of disease in these areas, owing to anatomical lymphatic drainage and pathologic information regarding the high incidence of hilar and mediastinal node metastasis. ${ }^{1}$ However, the overall survival of patients with stage III NSCLC remains poor.

Local recurrence is one reason for the poor survival rate after radiotherapy. A previous study reported that an improvement in local control leads to increased survival in locally advanced NSCLC. ${ }^{2}$ In order to improve local control without increasing normal tissue toxicity, involved-field radiation therapy (IFRT) using threedimensional conformal radiation therapy techniques for dose escalation has been considered. ${ }^{3-9}$ The rationale against elective nodal irradiation is the high local recurrence rates within the previously irradiated tumor volume and the high chance of distant metastasis. ${ }^{1}$ We thought that controlling the gross disease was more important than treating areas that might harbor microscopic disease. Treating locally advanced NSCLC with IFRT has generated concern for the increased risk of
1Department of Radiation Oncology, Hiroshima City Asa Citizens Hospital, Japan.
Corresponding author: Hiroshi Kiriu.

Received June 14, 2016; accepted September 1, 2016. 
nodal failure in untreated nodal stations, as clinically uninvolved lymph nodes may harbor microscopic disease. However, many authors have reported that elective nodal failure (ENF) occurs in fewer than $10 \%$ of cases. ${ }^{3-8}$ Given these findings, we decided to introduce IFRT for stage III NSCLC at our institution.

In RTOG 0617, Bradley et al. concluded that 74 Gy of radiation administered in 2-Gy fractions with concurrent chemotherapy was not better than 60 Gy plus concurrent chemotherapy for patients with stage III NSCLC and might be potentially harmful. ${ }^{10}$ These findings suggest that dose escalation using normal fractions (2 Gy/ fraction) might be unlikely to improve treatment outcomes because of the longer treatment duration. Shortening the overall treatment duration may instead be best for improving local control.

The purpose of this study was to evaluate the outcomes of patients with stage III NSCLC treated with IFRT and to compare the effects of conventional IFRT and hypofractionated IFRT.

\section{MATERIALS AND METHODS}

\section{Patient eligibility}

At Hiroshima City Asa Citizens Hospital, 51 patients with advanced NSCLC underwent IFRT from December 2004 to November 2015. The eligibility criteria were locally advanced stage IIIA disease or stage IIIB disease (excluding malignant pleural effusion, malignant pericardial effusion, or lymphangitic carcinomatosis), histologically or cytologically confirmed NSCLC, age over 20 years, Eastern Cooperative Oncology Group performance status of 0-2, and no prior therapy for this malignancy.

Before therapy, all patients were clinically evaluated with a medical history, physical examination, laboratory examination, and radiographic studies. The laboratory examination included a complete blood cell count, liver function studies, renal function studies, and measurement of electrolytes. The radiographic studies included chest radiography, thoracic abdominal computed tomography (CT), and head magnetic resonance imaging (MRI). Whole-body fluorodeoxyglucose-positron emission tomography (FDG-PET) scans were not routinely performed.

\section{Treatment procedure for IFRT}

For treatment planning, three-dimensional (3D) conformal radiation therapy was used for all patients. For $3 \mathrm{D}$ treatment planning, CT (LightSpeed RT; GE, Milwaukee, WI, USA) was performed under free-breathing conditions. CT volume data were then transferred to a $3 \mathrm{D}$ treatment planning system (Xio; ELEKTA, Stockholm, Sweden). A physician delineated the target volume on the axial CT slices. To determine the target volume, we delineated the primary tumor and lymph nodes that measured $>1 \mathrm{~cm}$ in the short axis as the gross target volume (GTV). A clinical target volume (CTV) margin of $5 \mathrm{~mm}$ was usually added to the GTV. A planned target volume margin of $8-12 \mathrm{~mm}$ was also usually added, which included the reproducibility of respiratory motion and setup error in the CTV. The prescribed dose was calculated with a heterogeneous dose calculation algorithm (super position). The patients treated with $2 \mathrm{~Gy} /$ fraction were enrolled in the conventional IFRT group and patients treated with $>2 \mathrm{~Gy} /$ fraction were enrolled in the hypofractionated IFRT group. In the patients treated using conventional IFRT, normal fractionation was used (2 Gy/fraction), and the total prescribed dose ranged from 60 to $66 \mathrm{~Gy}$. In the patients treated with hypofractionated IFRT, $2.5 \mathrm{~Gy} /$ fraction was used, and the total prescribed dose ranged from 65 to 70 Gy. Treatment was delivered using 6-10 MV photons from the linear accelerator. The volumes of lung tissue receiving a dose $\geq 20$ Gy (lung V20) and esophagus tissue receiving a dose $\geq 50$ Gy (esophagus V50) were kept to a minimum, since these parameters predict the risk of radiation pneumonitis and esophagitis. ${ }^{11}$

\section{Chemotherapy}

Thirty-four patients (75.6\%) were administered chemotherapy. The basic regimen was weekly carboplatin (area under the curve [AUC], 2.0) plus paclitaxel (40 mg/ $\left.\mathrm{m}^{2}\right)$ or cisplatin $\left(80 \mathrm{mg} / \mathrm{m}^{2}\right)$ plus vinorelbine $\left(25 \mathrm{mg} / \mathrm{m}^{2}\right.$ per day on days 1 and 8). Nineteen patients received carboplatin plus paclitaxel concurrently with IFRT. Eight patients received cisplatin plus vinorelbine concurrently. Six patients received S-1 because platinum was inadequate for their age and/or due to complications. Eleven patients (24.4\%) did not undergo chemotherapy because of the presence of various comorbidities and/or advanced age.

\section{Evaluation}

The tumor response rate was analyzed according to the Response Evaluation Criteria in Solid Tumors (RECIST) guidelines. We also evaluated the adverse effects, especially radiation pneumonitis and esophagitis, using Com- 
Table 1. Clinical Characteristics of NSCLC Patients

\begin{tabular}{|c|c|c|c|}
\hline & Conventional IFRT & Hypofractionated IFRT & $\mathrm{P}$ \\
\hline Gender & & & 0.2478 \\
\hline Male & 20 & 22 & \\
\hline Female & 3 & 0 & \\
\hline Age, years (median) & $50-89(75)$ & $57-81(68)$ & 0.2725 \\
\hline Histology & & & 0.9662 \\
\hline Adenocarcinoma & 6 & 5 & \\
\hline Squamous cell carcinoma & 15 & 15 & \\
\hline Others & 2 & 2 & \\
\hline TNM Stage & & & 0.0982 \\
\hline IIIA & 9 & 15 & \\
\hline IIIB & 14 & 7 & \\
\hline $\mathrm{T}$ factor & & & 0.3409 \\
\hline 1 & 3 & 1 & \\
\hline 2 & 4 & 6 & \\
\hline 3 & 4 & 7 & \\
\hline 4 & 12 & 7 & \\
\hline Unknown & 0 & 1 & \\
\hline $\mathrm{N}$ factor & & & 0.3761 \\
\hline 0 & 5 & 4 & \\
\hline 1 & 2 & 3 & \\
\hline 2 & 7 & 11 & \\
\hline 3 & 9 & 4 & \\
\hline Tumor position & & & 0.7003 \\
\hline Left upper lobe & 7 & 5 & \\
\hline Left lower lobe & 1 & 2 & \\
\hline Right upper lobe & 10 & 11 & \\
\hline Right lower lobe & 5 & 3 & \\
\hline Unknown & 0 & 1 & \\
\hline EGFR mutation & & & 0.5717 \\
\hline+ & 1 & 1 & \\
\hline- & 3 & 1 & \\
\hline Unknown & 2 & 3 & \\
\hline $\operatorname{ALK}(+)$ & 0 & 0 & - \\
\hline
\end{tabular}

There were no significant differences in the patients' characteristics between the two treatment groups.

mon Terminology Criteria for Adverse Events (CTCAE) version 4.0. In-field and out-of-field recurrences were assessed using varying combinations of radiological assessment. Local recurrence was defined as an increase in the rate of radiologic abnormalities within the irradiated volume that was not considered to be radiation-induced scarring or radiation pneumonitis. ENF was defined as recurrence in any lymph node region that was initially uninvolved, regardless of the presence of local failure or distant metastasis.

\section{Follow-up}

Patients were followed up at regular intervals, usually every 3-6 months for the first 1-3 years after treatment and then every $6-12$ months after 3 years if the patient had no evidence of recurrence. The follow-up evaluation routinely included a physical examination, chest radiography, and blood tests. CT scans of the thorax and abdomen were performed every 3-6 months.

\section{Statistical methods}

Univariate analyses using the Mantel-Haenszel $\chi^{2}$ test were performed to determine the statistical significance of differences in responses. The Kaplan-Meier method was used to calculate the overall survival and local control rates. Statistical significance was defined as $\mathrm{P}<0.05$.

\section{RESULTS}

\section{Patient characteristics}

Fifty-one patients with advanced NSCLC underwent 
Table 2. Details of Treatment

\begin{tabular}{|c|c|c|c|}
\hline \multicolumn{4}{|l|}{ Three-dimensional treatment planning } \\
\hline System & \multirow{2}{*}{\multicolumn{2}{|c|}{$\begin{array}{c}\text { Xio } \\
\text { super position }\end{array}$}} & \\
\hline Dose calculation algorithm & & & \\
\hline \multicolumn{4}{|l|}{ Dose } \\
\hline \multicolumn{4}{|l|}{ Conventional IFRT } \\
\hline 60-66 Gy/30-33 fractions (median $60 \mathrm{~Gy}$ ) & \multicolumn{2}{|c|}{24 patients } & \\
\hline \multicolumn{4}{|l|}{ Hypofractionated IFRT } \\
\hline 65-70 Gy/26-28 fractions (median 65 Gy) & \multicolumn{2}{|c|}{14 patients } & \\
\hline $72 \mathrm{~Gy} / 30$ fractions & \multicolumn{2}{|c|}{6 patients } & \\
\hline $60 \mathrm{~Gy} / 20$ fractions & \multicolumn{2}{|c|}{2 patients } & \\
\hline Concurrent Chemotherapy & Conventional IFRT & Hypofractionated IFRT & $\mathrm{P}=0.1850$ \\
\hline Weekly carboplatin + paclitaxel & 7 patients & 12 patients & \\
\hline Cisplatin + vinorelbine & 6 patients & 2 patients & \\
\hline Other & 0 patients & 1 patient & \\
\hline None or S-1 & 10 patients & 7 patients & \\
\hline
\end{tabular}

There were no significant differences in concurrent chemotherapy between the two treatment groups.

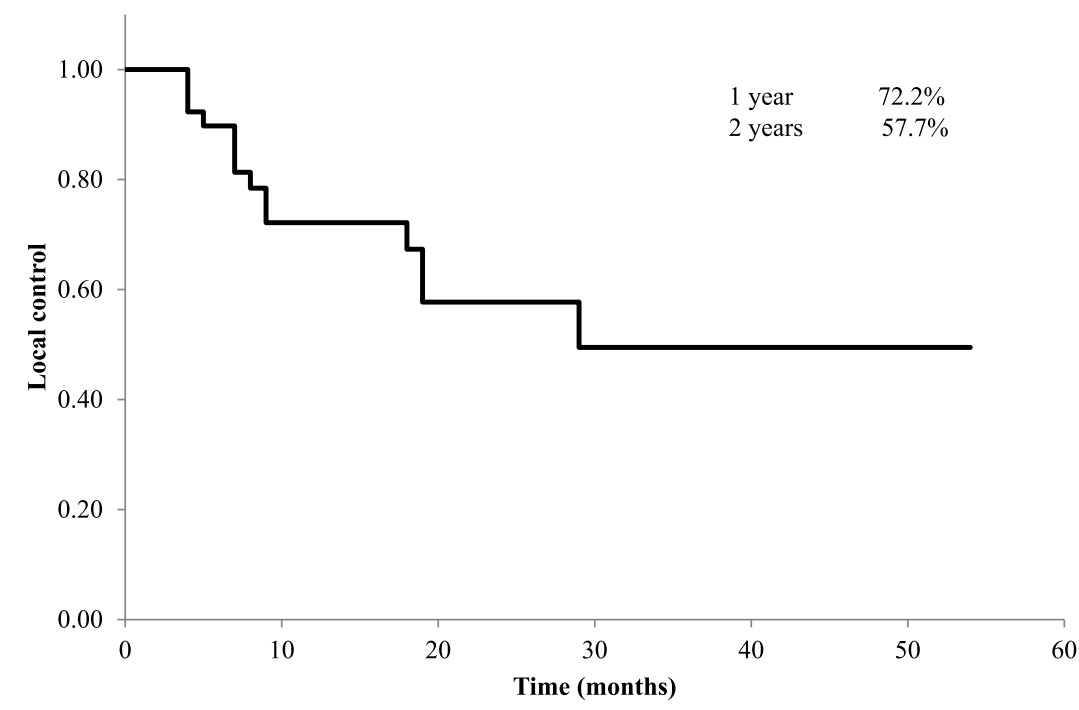

Number at risk

$\begin{array}{lllllll}45 & 21 & 14 & 11 & 7 & 4 & 2\end{array}$

Figure 1. Local control in 45 patients with stage III non-small-cell lung cancer after involved-field radiation therapy.

IFRT from December 2004 to November 2015. Among these, 45 patients were ultimately enrolled and evaluated. Six patients were excluded for the following reasons: 1 patient changed hospitals immediately after the treatment, and 5 had their dose prescription changed from 2 to $2.5 \mathrm{~Gy} /$ fraction during the treatment period.

The patients' clinical characteristics are summarized in Table 1. There were no significant differences in the clinical characteristics of the two groups. The median age was 69 years (range, 50-89 years), and 42 patients were men and 3 women. Eleven patients (24.4\%) presented with adenocarcinoma, 30 (66.7\%) with squamous cell carcinoma, and 4 (8.9\%) with other types. Twentyfour (53.3\%) had stage IIIA, and 21 (46.7\%) had stage IIIB disease. The details of their treatments are shown in Table 2 . 


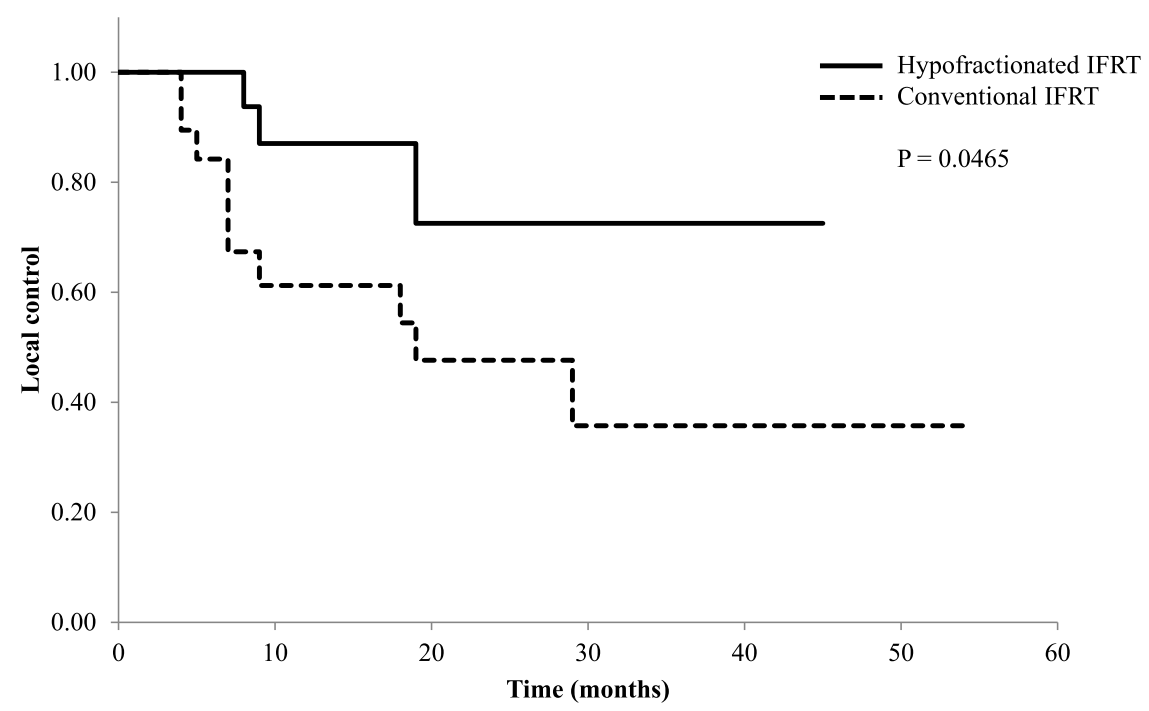

Number at risk

Hypofractionated IFRT 22

Conventional IFRT 23

11

11

6

8

Figure 2. Comparison of local control in 22 patients with stage III non-small-cell lung cancer after hypofractionated involved-field radiation therapy and in 23 patients after conventional involved-field radiation therapy.

Table 3. Pattern of First Failure

\begin{tabular}{lcr}
\hline & \multicolumn{2}{c}{ Patients $(\mathrm{n}=45)$} \\
& Number & (\%) \\
\hline None & 23 \\
Local recurrence & 7 \\
Local recurrence and ENF* & 2 \\
Local recurrence and distant & 2 \\
Local recurrence, ENF* and distant & 0 \\
ENF* only without local recurrence and distant & 1 & $(2.2)$ \\
ENF* and distant & 1 & \\
Distant only without local recurrence and ENF* & 9 & \\
\hline
\end{tabular}

*ENF: elective nodal failure.

\section{Local control rate and the pattern of first failure}

The follow-up duration at the time of evaluation ranged from 2 to 103 months (median 14 months). The 1 - and 2 year local control rates were $72.2 \%$ and $57.7 \%$, respectively (Figure 1). The patients in the conventional IFRT group had a 1-year local control rate of $61.2 \%$ and a 2 year local control rate of $47.6 \%$, while the patients in the hypofractionated IFRT group achieved higher local control rates of $87.1 \%$ and $72.5 \%$, respectively $(\mathrm{P}=0.0465$, Figure 2). The patterns of first failure are shown in Table 3 . Of the 45 patients, disease recurrence was recorded in 22 patients. Local recurrence occurred in 11 patients $(24.4 \%)$, distant metastases in 12 patients (26.7\%), and ENF in 4 patients (8.9\%). ENF alone was observed in 1 patient (2.2\%).

\section{Overall survival}

The 1- and 2-year overall survival rates were $78.4 \%$ and $53.7 \%$, respectively (Figure 3 ). The patients in the conventional IFRT group had a 1-year overall survival rate of $72.7 \%$ and a 2 -year overall survival rate of $44.8 \%$, while patients in the hypofractionated IFRT group tended to have a higher overall survival rate $(86.6 \%$ and $72.2 \%$, respectively; $\mathrm{P}=0.0681$, Figure 4). 


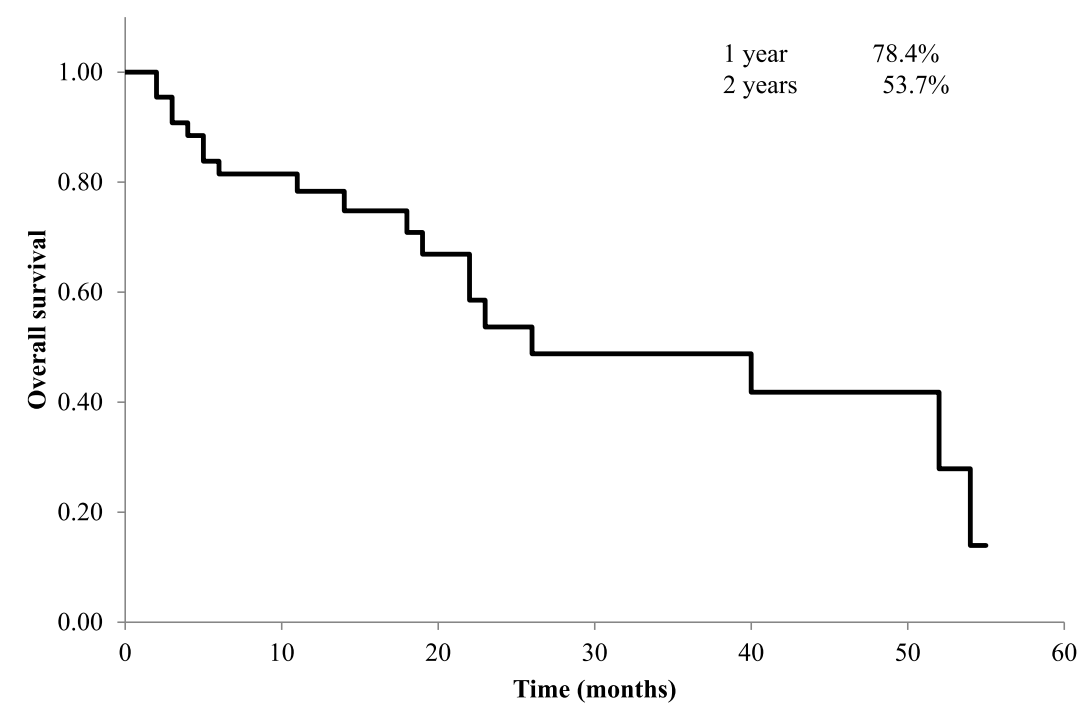

Number at risk

$\begin{array}{lllllll}45 & 28 & 18 & 11 & 7 & 4 & 1\end{array}$

Figure 3. Overall survival in 45 patients with stage III non-small-cell lung cancer after involved-field radiation therapy.

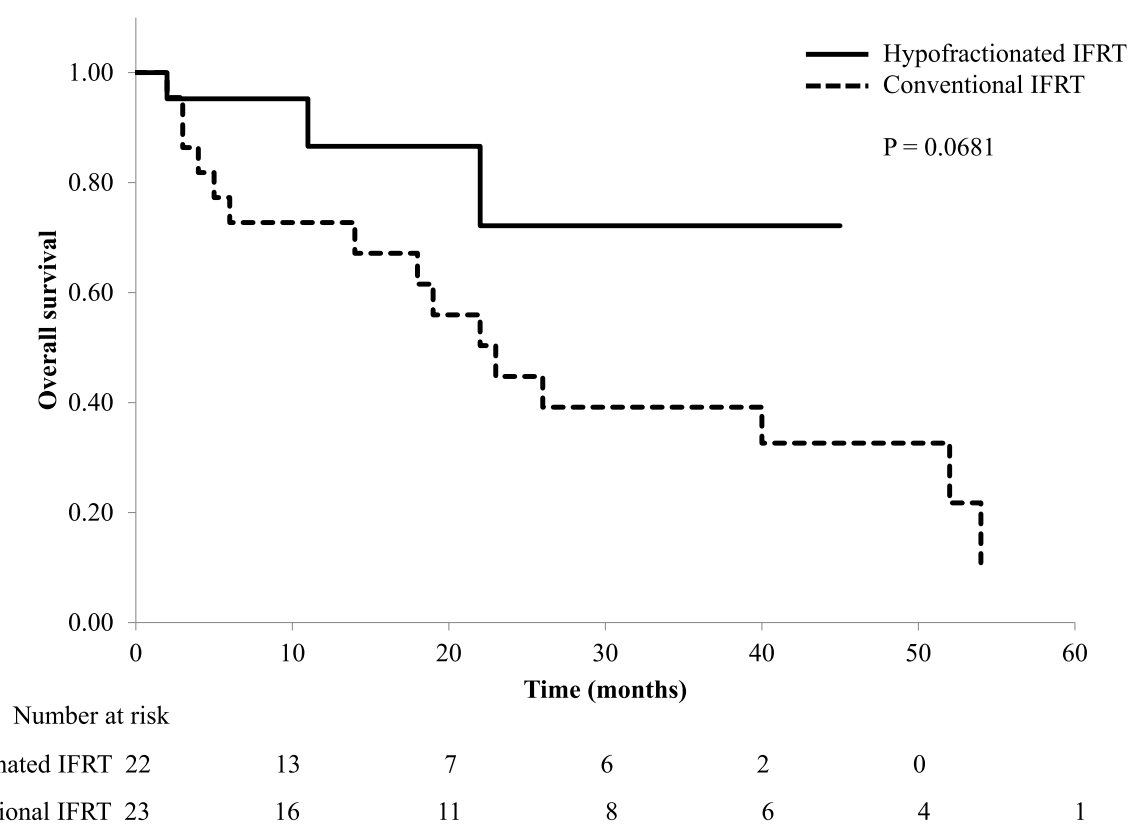

Figure 4. Comparison of the overall survival in 22 patients with stage III non-small-cell lung cancer after hypofractionated involved-field radiation therapy and in 23 patients after conventional involved-field radiation therapy.

\section{Treatment-related toxicities}

Grade 1 radiation pneumonitis was detected in 26 patients (57.8\%), grade 2 in 11 patients $(24.4 \%)$, and grade 3 in 3 patients $(6.7 \%)$. Grade 2 or worse radiation pneumonitis was observed in 7 patients treated with conventional IFRT and in 7 patients with hypofractionated
IFRT, respectively. Grade 1 radiation esophagitis was detected in 6 patients $(13.3 \%)$ and grade 2 radiation esophagitis in 12 patients (26.7\%), with no patients showing higher than grade 3 radiation esophagitis. Grade 2 radiation esophagitis was observed in 7 patients treated with conventional IFRT and in 5 patients with hypofrac- 
Table 4. Details of the Treatment Toxicity and DVH Analysis

\begin{tabular}{lccc}
\hline Toxicity & Conventional IFRT & Hypofractionated IFRT & P \\
\hline Radiation pneumonitis & & & \\
Grade 2 & 4 & 7 & 0.4361 \\
Grade 3 & 3 & 0 & 0.2478 \\
Lung V20 & $14.5-44.0$ (median 21.2) & 13.6-48.7 (median 20.5) & 0.5418 \\
Radiation esophagitis & & & \\
Grade 1 & 7 & 4 & 0.6191 \\
Grade 2 & $0-42.0$ (median 16.8) & $0.7-39.3$ (median 15.1) & 0.6275 \\
Esophagitis V50 & & &
\end{tabular}

DVH, dose volume histogram.

Table 5. Prognostic Factors on a Univariate Analysis

\begin{tabular}{|c|c|c|c|c|c|}
\hline Prognostic factor & & $\begin{array}{c}\text { 2-year overall survival } \\
(\%)\end{array}$ & $\begin{array}{l}\text { UVA } \\
\mathrm{P}\end{array}$ & $\begin{array}{c}\text { 2-year local control } \\
(\%)\end{array}$ & $\begin{array}{l}\text { UVA } \\
\mathrm{P}\end{array}$ \\
\hline \multirow[t]{2}{*}{ Age, years } & $<75$ & 76.2 & $0.0053 *$ & 63.6 & 0.2109 \\
\hline & $\geq 75$ & 12.9 & & 48.0 & \\
\hline \multirow[t]{2}{*}{$\mathrm{T}$ factor } & $\leq \mathrm{T} 3$ & 50.4 & 0.7758 & 46.5 & 0.9701 \\
\hline & $\mathrm{T} 4$ & 48.6 & & 60.1 & \\
\hline \multirow[t]{2}{*}{$\mathrm{N}$ factor } & $\leq \mathrm{N} 2$ & 58.9 & 0.6209 & 67.7 & 0.0827 \\
\hline & N3 & 48.9 & & 27.8 & \\
\hline \multirow[t]{2}{*}{ TNM stage } & IIIA & 55.5 & 0.6695 & 73.8 & 0.1238 \\
\hline & IIIB & 49.3 & & 39.3 & \\
\hline \multirow[t]{2}{*}{ Chemotherapy } & Intravenous chemotherapy & 76.7 & $0.0198 *$ & 57.7 & 0.7890 \\
\hline & None or S-1 & 36.0 & & 60.8 & \\
\hline \multirow[t]{2}{*}{ Radiotherapy } & Conventional IFRT & 44.8 & 0.0681 & 47.6 & $0.0465^{*}$ \\
\hline & Hypofractionated IFRT & 72.3 & & 72.5 & \\
\hline
\end{tabular}

UVA, univariate analysis.

$* \mathrm{P}<0.05$.

Table 6. Summary of Involved-field Radiation Therapy for Non-small-cell Lung Cancer

\begin{tabular}{|c|c|c|c|c|c|c|c|}
\hline $\begin{array}{c}\text { Author } \\
\text { (year) }\end{array}$ & $\begin{array}{c}\text { Number of } \\
\text { patients, } \\
\text { stage IIIB (\%) }\end{array}$ & $\begin{array}{c}\text { Concurrent } \\
\text { radiotherapy }+ \text { chemotherapy }\end{array}$ & $\begin{array}{l}\text { Local control rate } \\
\text { (\%@years) }\end{array}$ & $\begin{array}{l}\text { Overall survival rate } \\
\text { (\%@years) }\end{array}$ & $\begin{array}{l}\text { ENF } \\
\text { alone } \\
(\%)\end{array}$ & $\begin{array}{l}\text { Esophagitis } \\
\text { Grade 3/4 }\end{array}$ & $\begin{array}{c}\text { Pneumonitis } \\
\text { Grade 3/4 }\end{array}$ \\
\hline $\begin{array}{l}\text { Yuan } \\
(2007)\end{array}$ & $\begin{array}{c}100 \\
39(39 \%)\end{array}$ & $\begin{array}{c}\text { 68-74 Gy/34-37 fractions } \\
\text { CBDCA + PTX }\end{array}$ & $\begin{array}{l}59 \% @ 2 \text { years } \\
51 \% @ 5 \text { years }\end{array}$ & $\begin{array}{l}39.4 \% @ 2 \text { years } \\
25.1 \% @ 5 \text { years }\end{array}$ & $7 \%$ & $1 \%$ & $4 \%$ \\
\hline $\begin{array}{l}\text { Matsuura } \\
(2009)\end{array}$ & $\begin{array}{c}10 \\
9(90 \%)\end{array}$ & $\begin{array}{c}62.5 \mathrm{~Gy} / 25-28 \text { fractions } \\
\text { CBDCA + PTX }\end{array}$ & 45\%@2 years & 43.7\%@2 years & $0 \%$ & $0 \%$ & $0 \%$ \\
\hline $\begin{array}{l}\text { Fernandes } \\
\text { (2010) }\end{array}$ & $\begin{array}{c}48 \\
-\end{array}$ & $\begin{array}{c}\text { 60-68 Gy/30-34 fractions } \\
\text { CDDP + ETP }\end{array}$ & $59.6 \% @ 2$ years & 43.7\%@2 years & $12.5 \%$ & $18.8 \%$ & $16.7 \%$ \\
\hline $\begin{array}{c}\text { Kimura } \\
(2010)\end{array}$ & $\begin{array}{ll}50 \\
30(60 \%)\end{array}$ & $\begin{array}{c}\text { 60-70 Gy/30-35 fractions } \\
\text { CBDCA + DTX }\end{array}$ & $58.4 \% @ 2$ years & $65.3 \% @ 2$ years & $8.2 \%$ & $8 \%$ & $0 \%$ \\
\hline $\begin{array}{l}\text { Chen } \\
(2013)\end{array}$ & $\begin{array}{cl}45 \\
30 & (67 \%)\end{array}$ & $\begin{array}{c}\text { 38-74 Gy/19-37 fractions } \\
\text { CBDCA + PTX }\end{array}$ & $62.9 \% @ 2$ years & 36.6\%@3 years & $4.4 \%$ & $0 \%$ & $4.4 \%$ \\
\hline $\begin{array}{l}\text { This study } \\
\text { (2016) }\end{array}$ & $\begin{array}{c}45 \\
21(47 \%)\end{array}$ & $\begin{array}{c}\text { 60-72 Gy/20-33 fractions } \\
\text { CBDCA + PTX }\end{array}$ & $57.7 \% @ 2$ years & $53.7 \% @ 2$ years & $2.2 \%$ & $0 \%$ & $6.7 \%$ \\
\hline
\end{tabular}

CBDCA, carboplatin; PTX, paclitaxel; CDDP, cisplatin; DTX, docetaxel; ETP, etoposide; ENF, elective nodal failure.

tionated IFRT, respectively. A dose volume histogram analysis showed that there were no significant differences in the volume of lung V20 and esophagus V50 be- tween the two groups. The details of toxicity are summarized in Table 4. 


\section{Prognostic factors}

Table 5 shows the results of univariate analyses for the overall and local control rates. Age $(<75$ years) and chemotherapy (intravenous chemotherapy) were significant predictive factors of a longer overall survival duration in the univariate analysis $(\mathrm{P}=0.0053$ and 0.0198 , respectively). Although no significant differences were noted between the two groups, radiotherapy (hypofractionated IFRT) tended to lead to superior overall survival ( $\mathrm{P}$ $=0.0681$ ). In addition, radiotherapy (hypofractionated IFRT) was a significant predictor of the local control rate $(\mathrm{P}=0.0465)$.

\section{DISCUSSION}

Concurrent chemoradiation is the standard of care for unresectable stage III NSCLC, but the overall survival remains poor because of the high local and distant recurrence rates. Dose escalation is one way to improve the local control rate and survival. Yuan et al. ${ }^{5}$ concluded that patients treated with IFRT achieved a better overall response and local control rate than patients treated with ENI, and IFRT allowed for a dose of 68 to 74 Gy to be safely administered to patients with inoperable stage III NSCLC. Several studies of IFRT for patients with locally advanced NSCLC reported better treatment outcomes than traditional chemoradiation studies. ${ }^{12-15}$ Table 6 lists the results of IFRT studies for locally advanced NSCLC. However, in the RTOG 0617 study, Bradley et al. concluded that $74 \mathrm{~Gy}$ of radiation administered in 2 Gy fractions with concurrent chemotherapy was not better than 60 Gy plus concurrent chemotherapy for patients with stage III NSCLC and might be potentially harmful. ${ }^{10}$ We therefore do not feel that dose escalation for patients with stage III NSCLC is inappropriate, but dose escalation using normal fractions (2 Gy/fraction) might be unlikely to improve treatment outcomes because of the longer treatment duration.

Matsuura et $\mathrm{al}^{3}$ reported that the 1-, 2-, and 3-year overall survival rates for NSCLC with hypofractionated IFRT were $90.0 \%, 58.3 \%$, and $43.8 \%$, respectively. Their treatment consisted of IFRT in fractions of $2.5 \mathrm{~Gy}$ for a median total dose of 65 Gy with weekly carboplatin plus paclitaxel. They concluded that hypofractionated IFRT with weekly carboplatin plus paclitaxel was a feasible treatment regimen. In our study, the 1- and 2-year overall survival rates were $78.4 \%$ and $53.7 \%$, respectively. In the 22 patients in the hypofractionated IFRT group, the
1- and 2-year overall survival rates were $86.6 \%$ and $72.2 \%$, respectively, and the 1 - and 2 -year local control rates were $72.2 \%$ and $57.7 \%$, respectively. The patients in the conventional IFRT group had a 1-year local control rate of $61.2 \%$ and a 2 -year local control rate of $47.6 \%$, while the patients in the hypofractionated IFRT group achieved a higher local control rate of $87.1 \%$ and $72.5 \%$, respectively $(\mathrm{P}=0.0465)$. Therefore, IFRT and hypofractionation may contribute to improvement in local control and overall survival.

The usefulness of the IFRT technique for advanced NSCLC, whether ENI is necessary or not, is controversial. Many authors have reported that ENF occurs in fewer than $10 \%$ of cases. $^{3-8}$ Kimura et al. concluded that a high dose of incidental irradiation may contribute to a low incidence of ENF in patients who have received IFRT. ${ }^{4}$ In our study, ENF was observed in 4 patients (8.9\%), and ENF alone was observed in 1 patient (2.2\%). Compared to other reports, this was not inferior.

Several studies of ENI have reported that grade 3/4 radiation esophagitis occurred in $20-30 \%$ of the patients. ${ }^{13-15}$ Studies of IFRT have reported that grade $3 / 4$ radiation esophagitis occurred in $0-20 \%$ of the patients. ${ }^{3-8}$ In our study, the incidence of radiation esophagitis was grade 2 in 12 patients (26.7\%), with no patients showing higher than grade 3 radiation esophagitis. The incidence of radiation pneumonitis was grade 2 in 11 patients (24.4\%) and grade 3 in 3 patients (6.7\%). These results are highly consistent with those of other reports.

\section{CONCLUSION}

IFRT for patients with stage III NSCLC is feasible, and the incidence of ENF was low. Our study was limited by a relatively short follow-up in patients treated with hypofractionated IFRT. However, hypofractionated IFRT may help improve the local control and overall survival rates.

本論文内容に関連する著者の利益相反：なし

\section{REFERENCES}

1. Chang JY, Bradley JD, Govindan R, Komaki R. Lung. In: Halperin EC, Perez CA, Brady LW, eds. Principles and practice of radiation oncology. 5 th ed. Philadelphia: Lippincott Williams \& Wilkins; 2008:1076-1108.

2. Schaake-Koning C, van den Bogaert W, Dalesio O, Festen J, Hoogenhout J, van Houtte P, et al. Effects of concomitant cisplatin and radiotherapy on inoperable 
non-small-cell lung cancer. N Engl J Med. 1992;326:524-530.

3. Matsuura K, Kimura T, Kashiwado K, Fujita K, Akagi Y, Yuki S, et al. Results of a preliminary study using hypofractionated involved-field radiation therapy and concurrent carboplatin/paclitaxel in the treatment of locally advanced non-small-cell lung cancer. Int J Clin Oncol. 2009; 14:408-415.

4. Kimura T, Togami T, Nishiyama Y, Ohkawa M, Takashima H. Impact of incidental irradiation on clinically uninvolved nodal regions in patients with advanced non-small-cell lung cancer treated with involved-field radiation therapy: does incidental irradiation contribute to the low incidence of elective nodal failure? Int J Radiat Oncol Biol Phys. 2010;77:337-343.

5. Yuan S, Sun X, Li M, Yu J, Ren R, Yu Y, et al. A randomized study of involved-field irradiation versus elective nodal irradiation in combination with concurrent chemotherapy for inoperable stage III nonsmall cell lung cancer. Am J Clin Oncol. 2007;30:239-244.

6. Rosenzweig KE, Sura S, Jackson A, Yorke E. Involvedfield radiation therapy for inoperable non small-cell lung cancer. J Clin Oncol. 2007;25:5557-5561.

7. Fernandes AT, Shen J, Finlay J, Mitra N, Evans T, Stevenson J, et al. Elective nodal irradiation (ENI) vs. involved field radiotherapy (IFRT) for locally advanced non-small cell lung cancer (NSCLC): A comparative analysis of toxicities and clinical outcomes. Radiother Oncol. 2010;95:178-184.

8. Chen M, Bao Y, Ma HL, Hu X, Wang J, Wang Y, et al. Involved-field radiotherapy versus elective nodal irradiation in combination with concurrent chemotherapy for locally advanced non-small cell lung cancer: a prospective randomized study. Biomed Res Int. 2013;2013:371819.

9. Kimura T, Hirokawa Y, Murakami Y, Kenjo M, Kaneyasu Y, Naito A, et al. The preliminary results of accelerated hyperfractionated radiotherapy with involved-field omitted elective nodal irradiation (ENI) for inoperable advanced non-small cell lung cancer (in Japanese with English abstract). J Jpn Soc Ther Radiol Oncol. 2004;16:79-84.

10. Bradley JD, Paulus R, Komaki R, Masters G, Blumenschein G, Schild S, et al. Standard-dose versus high-dose conformal radiotherapy with concurrent and consolidation carboplatin plus paclitaxel with or without cetuximab for patients with stage IIIA or IIIB non-smallcell lung cancer (RTOG 0617): a randomised, two-by-two factorial phase 3 study. Lancet Oncol. 2015;16:187-199.

11. Werner-Wasik M, Yorke E, Deasy J, Nam J, Marks LB. Radiation dose-volume effects in the esophagus. Int $J$ Radiat Oncol Biol Phys. 2010;76(Suppl):S86-S93.

12. Curran WJ, Scott CB, Langer CJ, Komaki R, Lee JS, Hauser S, et al. Long-term benefit is observed in a phase III comparison of sequential vs concurrent chemoradiation for patients with unresected stage III NSCLC: RTOG 9410. Proc Am Soc Clin Oncol. 2003;22:621 (abstract 2499).

13. Zatloukal P, Petruzelka L, Zemanova M, Havel L, Janku F, Judas L, et al. Concurrent versus sequential chemoradiotherapy with cisplatin and vinorelbine in locally advanced non-small cell lung cancer: a randomized study. Lung Cancer. 2004;46:87-98.

14. Belani CP, Choy H, Bonomi P, Scott C, Travis P, Haluschak J, et al. Combined chemoradiotherapy regimens of paclitaxel and carboplatin for locally advanced non-small-cell lung cancer: a randomized phase II locally advanced multi-modality protocol. J Clin Oncol. 2005;23: 5883-5891.

15. Fournel P, Robinet G, Thomas P, Souquet PJ, Léna H, Vergnenégre A, et al. Randomized phase III trial of sequential chemoradiotherapy compared with concurrent chemoradiotherapy in locally advanced non-small-cell lung cancer: Groupe Lyon-Saint-Etienne d'Oncologie Thoracique-Groupe Français de Pneumo-Cancérologie NPC 95-01 Study. J Clin Oncol. 2005;25:5910-5917. 